\title{
Exploring the Aspectual Constraints on the BA Resultative in Mandarin Chinese
}

\author{
Jing Han
}

\begin{abstract}
This paper explores the aspectual constraints of the resultative expressions involving BA in Mandarin Chinese, in terms of telicity and perfective viewpoint. On the one hand, the telicity does not merely come from the aspect marker but also springs from the aspectual feature of the BA resultative per se, on the basis of an all-around comparison between the BA resultatives and the canonical expressions. While discussing the telicity in the BA resultatives, it is also necessary to consider the non-homogeneous feature and the role of the resultative element. On the other hand, this paper proposes the perfective aspectual model of the BA resultatives the analysis of which can be further combined with a sequence of three distinct time points including Event Time, Speech Time, and Reference Time. This investigation is followed by the representation of how the perfectivity is projected onto the time scale including the past perfect and the future perfect. This paper also mentions the semantic meaning of the BA expression.
\end{abstract}

Index Terms-Aspect, perfectivity, resultative, telicity.

\section{INTRODUCTION}

This paper explores the aspectual constraints of the resultative expressions involving BA in Mandarin Chinese, in terms of telicity and perfective viewpoint. I argue in this paper that an Expression involving BA is telic by using two criteria, i.e. "endpoint" and "non-homogeneity".

The telicity is to a large extent contributed by the [+telic] feature of the resultative Expression involving BA per se, rather than (or, at least, not only due to) the aspect marker le, based on the contrast between the [+telic] Expression involving $\mathrm{BA}$ and the [-telic] transitive expression. An Expression involving BA depicts a telic event with an inherent entailment of completion: there is a culmination point at which the action designated by the main verb comes to an end and cannot continue further. Meanwhile, this paper finds that the resultative Expression involving $\mathrm{BA}$ is non-homogeneous.

While discussing the telicity in Expressions involving BA, it is necessary to consider the role of the resultative element as well. The study puts forward the perfective aspectual model of the BA resultative and the aspectual analysis is further combined with a sequence of three distinct time points including Event Time (E), Speech Time (S), and Reference Time $(\mathrm{R})$ : the perfectivity is projected onto the time scale, including the past perfect and the future perfect.

Manuscript received January 20, 2016; revised June 3, 2016.

Jing Han is with the School of Foreign Languages, Shanghai University, Shanghai, 200444 China (e-mail: hanjing99@shu.edu.cn).

\section{TELICITY AND PERFECTIVITY}

Telicity is related to the fact that whether the entire event still exists or not. This definition involves identification of truth condition. Previous arguments on telicity can be found in the work of [1] (pp. 42-49), [2], [3] (pp.150-180), [4]-[7].

Providing that telicity entails the boundary of an event; therefore, the bounded event is supposed to be telic while the event with a not clear boundary is atelic. The former event must have already finished within a prescribed scale of time, whereas the unbounded event is not necessarily the case. This problem also pertains to the relationship between the reference time, speech time and event time. Another question arises, i.e., what is the origin of the telic event? There are lots of completed events in the real world. To take the sentence of Stephen Hawking graduated from Oxford University for example, the proposition in question suggest an event which has already finished in the past with a clear ending point, considering the finished period of time in the past tense no longer holds.

Telicity refers a bounded event in which there is a clear-cut beginning point together with ending point of an entire event. Atelicity gets involved in an unbounded event which does not have a clear boundary. In other words, the atelic event is homogenous and each section of this event has the same properties which can be shared by all.

To compare the following two sentences: (a) She painted for 2 hours; (b) She painted a picture in 2 hours. In sentence (a), this is an atelic event in which what she did at the point of 0.5 hour, 1 hour, and two hours was the same without difference. By contrast, sentence (b) describes a telic event with at least one bounded part with a clear end point involved. What she did at the point of 1 hour and what she did at the point of two hours were not the same, because this was specifically an entire activity in which she was gradually and progressively finishing her painting a picture. There is much difference among her achieved at different time points in this dynamic and non-homogenous event. The existence of a boundary is an indispensible part for a telic clause in which the predicate can be made true. Otherwise, severe contradiction would occur to the truth of the sentence in question.

Based on the above analyses, we can see that the critical discrepancy between telicity and atelicity is whether there is at least an inherent boundary involved in the event described or presented, not to mention the existent a tons of conceptual and cognitive tests conducted in the field of proving telicity.

It is frequently seen that adverbials combined with telicity involve in duration which indicates how much time is spent to achieve the final target or result which is gradually obtained 
based on all the previous steps. However, atelicity is more frequently combined with for duration time which suggests that each part of the whole event is equal and homogenous without differences accumulated gradually. This involves ambiguity somehow. It is promising to explore the semantics domains of telicity and atelicity in the conceptual framework and the discourse context.

Perfectivity is related to, but not the same with telicity [8]. Telicity is a kind of relationship held between conditional truth and time scale. Perfectivity is not attributed to telicity the definition of which has just been discussed. There are a series of tests which can be used to show the difference between the telic and atelic clauses such as the validity of sentences with or without the existence of adverbials.

Alike, the progressive clause largely has to do with the existence of telicity; only if the entire event is borne with a clear and inherent boundary, this event is possible to be imperfective. This does not mean atelic predicates can never appear with perspective aspect. By contrast, atelic verbs can also occur with perfectives. Nonetheless, the interpretation of the unbounded meaning as atelicity shows will totally be changed into bounded reading. The reason is that atelicity dose never shows the event starts from which specific time point and ends at which specific time point, so that we will not be able to make assumptions on what is different among various phases.

In terms of syntactical diagnostics, there are also a series of methods for one to identify telicity and atelicity [9]. For example, there is a strict selection of verbs which are entitled to entry into telic clauses. Those verbs which cannot be able to describe or indicate changing status and bounded event are forbidden into the telic clauses. In contrary, verbs which inherently have the meaning relevant to change of action or activity have entry into telic clause. Some prepositional phrases which cannot show the duration of time in which an entire and bounded event occurs are also not permitted to enter telic clauses. Only those prepositional phrases such as in duration phrases as mentioned earlier in this article can do so.

For another example, only transitivity can appear with telicity whereas atelicity cannot be co-present with transitive clauses, which have received a deal of attention [10]. However, this connection between transitivity and telicity is not necessarily robust, particularly based on data obtained from the experiment and tests in the field of second language acquisition. Since this is not the foci of this study, discussions are not unfolded here. Some other linguistic tests including whether the involvement of (in) direct object makes impact on telicity has been discussed pertaining to approaching the nature of telicity and atelicity based on which perspective aspect is founded.

All above devices are employed to indicate the essential factor for establishing telicity. This has fundamental effect on selection and use of predicate verbs, prepositional phrases and modifiers and so on, which contribute to the syntactical features and structure of the telic and atelic clauses.

Above all, telicity does not necessarily lead to perfectivity. The supporting evidence is that there are a lot of non-perfective clauses which do not contain telic verbs. We can see that atelic clauses could be not perfective. There is no relationship between telicity and perfectivity through the test of adverbials. This test could be applied into a number of languages.

Both perfective and non-perfective clauses could be found with existence of various types of adverbials. Atelic verbs could also be allowed to appear in perfective clauses. Instances can be understood as a progressive event or action, which has been demonstrated across different languages. One verb predicate functions as telic while the other atelic. The result of the modifiers test is that both telic and atelic verbs could co-occur with perfective clauses.

It has been established that telicity does not necessarily result in perfectivity. In fact, telicity does not play an indispensible role in realizing perfectivity. Regarding another assumption whether perfectivity leads to telicity, a group of tests could be adopted to examine co-occurence of adverbials with types of verbs are acceptable or permitted in the utterance of speech.

The tests show that the combination of different verbs and adverbials make different readings with even vague perception. The similar finding is obtained through the parallel test which shows that the possible interpretation with telic verbs can be rather invalid with atelic ones as presented in behaviors of adjusted structure.

Moreover, the entry of the telic verb can be forbidden into the progressive aspect, not only in English but also in other languages. When the entry is allowed, it could be almost ascertained that there is an atelic verb in the clause in question.

TABLE I: INHERENT BOUNDARY OF TELICITY

\begin{tabular}{|l|c|c|}
\hline Inherent endpoint & + & - \\
\hline Bounded & + & + \\
\hline Telic & + & - \\
\hline Progressive acceptable? & + & - \\
\hline
\end{tabular}

All above tests reveal the convergent finding, that is, the perfective verb gives rise to telicity while the non-perfective verb results in atelic function, although there is not a solid relationship between telic and atelic state supposing the perfectivity is settled down in a given clause.

To take all the findings into account, we summarize the findings as follows: telicity does not necessarily yield perfectivity, whereas perfectivity does not necessarily lead to telicity. There is not a bound tie between perfectivity (imperfectivity) and telicity (atelicity). Therefore, it is suggested to discuss these two parts separately rather than mixing them together. These have something to do with three times including reference time, speech time etc. However, tense and aspect may also be set apart from the perspective of convenient discussion.

\section{TELICITY OF THE BA RESUlTATIVES}

An Expression involving BA is telic by using two criteria, i.e. "endpoint" and "non-homogeneity" [11]. The notion of "endpoint" has been seen in a great deal of literature. A telic event is "viewed as a whole" with "the beginning" and "the end" [12] (pp. 17-20). For example, the instance (1) expresses an event which involves the completion of the action chui 
('blow'): the object zhe-zhi xiao-deng ('this small candle') ends in stopping working.

(1) Wo ba zhe-zhi xiao-deng zhouran-de chui xi 1SG BA DEM-CL small-candle suddenly blow out 'I suddenly blew this small candle out.'

It could be questioned whether the telicity in (1) merely comes from the aspect marker le. However, the Chinese aspect marker le does not necessarily indicate completion, which leads to the imperfective paradox. As in (1), le conjoins the predicate, but the whole event is not completed as indicated by the clause (in italics) keshi mei xie-wan ('but not write-finish (it)').

(2) Wo zuotian xie LE yi-feng xin, keshi mei xie-wan. 1SG yesterday write LE one-CL letter, but not write-finish

'I wrote a letter yesterday, but I didn't finish it.'

(Tai 1984) [13]

Hence, the telicity in (1) is to a large extent contributed by the [+telic] feature of the resultative Expression involving BA per se, rather than (or, at least, not only due to) the aspect marker le. The contrast between the [+telic] Expression involving BA and the [-telic] transitive expression can be seen from the following examples:

(3) *Wo ba ta tuo hui matou le, you tuo dao langqiao. 1SG BA 3SG drag back to dock ASP further drag to bridge

'I dragged him back to the dock, and I dragged (him) further to the bridge.'

(4) Wo tuo ta hui matou le, you tuo dao langqiao. 1SG drag 3SG back to dock ASP further drag to bridge

'I dragged him back to the dock, and I dragged (him) further to the bridge.'

As shown in (3), an Expression involving BA depicts a telic event with an inherent entailment of completion: there is a culmination point at which the action designated by the main verb tuo ('drag') comes to an end and cannot continue further. That is, the $3 \mathrm{SG}$ object is dragged by the $1 \mathrm{SG}$ subject back to the dock, and thus 'his' location has been changed. That is the end. Therefore, the resultative Expression involving BA (3) cannot conjoin with another clause as in italics, i.e. 'I dragged him further to the bridge'. In contrast, the transitive instance
(4) could describe an event which is not finished and thus the state of the object is subject to new change, i.e. 'I dragged him further to the bridge'.

As mentioned in the beginning of this paper, telicity is defined also by non-homogeneity which means one part is not the same with the whole event. The resultative Expression involving BA is non-homogeneous (or, non-cumulative): The main predicate in an Expression involving BA always has a heterogeneous feature involving a natural endpoint which characterizes telicity, such as tuo ('drag') in (3). In an activity of 'dragging', any part of the event is not the same with the whole event, with an implied endpoint. The telic predicate features [+ADD TO] creating a path along which the event is unfolded towards a termination. This feature is not found in these non-telic verbs, such as a mental verb ai ('love') in (5):

(5) *Wo BA ta ai shang le 1SG BA 3SG love up ASP ?? 'I fell in love with him/her/it.'

As shown in (5), the non-telic verb ai ('love') is not appropriate in an Expression involving BA: it does not depict a non-homogeneous event in which the object can be totally affected in an ongoing and measurable process.

While discussing the telicity in Expressions involving BA, it is necessary to consider the role of the resultative element. On the one hand, the resultative generally suggests a boundary/endpoint for a telic event, such as hui matou ('back to the dock') in (3). On the other, the resultative features "[+SQA]" ("specific quantity of A") providing a "measuring out" (Tenny 1994) for the main verb. Still in (3), for example, hui matou ('back to the dock') indicates the measurable progress of the action tuo ('drag'), i.e. to which stage the event tuo has reached.

\section{Perfective ViewPoint of the BA Resultatives}

Smith (1991: 127) [14] (pp. 120-140) introduces three "view points" including Perfective, Imperfective, and Neutral. The perfective viewpoint refers to a "situation as a whole with initial and final points". In the resultative Expressions involving BA, the change into a new state (i.e. the result), cannot be seen until the event reaches the endpoint. In an instance (1) of an Expression involving BA, the resultative $x i$ ('be out') immediately occurs after the action chui ('blow') finishes, without time delay. The following Fig. 1 represents the perfective viewpoint of the resultative Expressions involving BA:

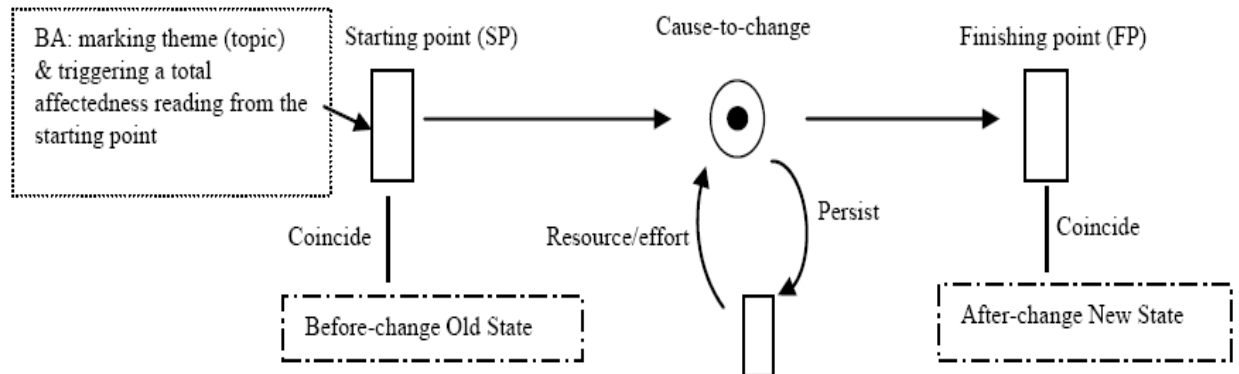

Fig. 1. Perfective aspectual model of the resultative expressions involving BA. 
Now I explain how Fig. 1 represents the event encoded by an Expression involving BA relative to perfectivity. Temporal parameters are not considered here but will be taken into account in Fig. 2 and Fig. 3. As shown above, there is a starting point (SP) and a finishing point (FP) and an intervening process of cause-to-change. The starting and the finishing points are illustrated by two blank squares on two sides. The object marker BA marks the theme-topic and elicits a total affectedness reading from the starting point, which is attributed to the prominent object in a pre-verbal position.

As illustrated by two dashed boxes in the bottom, there are 'Before-change Old State' and 'After-change New State' which occur at the starting point and the finishing point, respectively. The Before-change Old State literally coincides with the state of the object before change, which can be presupposed by the main predicate. By comparison, the After-change New State cannot be seen until the finishing point. The new state is syntactically expressed by the resultative element in a post-verbal position. The operation in the middle of the diagram represents the change-action designated by the main predicate in an Expression involving BA. The before-change state and the after-change state are the windowed parts.

As far as the gapped part is concerned, the intervening cause-to-change process is accompanied with mechanisms such as Persist and Resource/Effort. Such mechanisms are involved in a dynamic circle consistently acting upon the target-object: resources/efforts are provided to drive the circle running, which results in the object in a changing mode. Only when the event arrives at the finishing point (FP), the 'After-change New State' can be observed.

The aspectual analysis in Fig. 1 can be further combined with a sequence of three distinct time points including "Event Time (E)", "Speech Time (S)", and "Reference Time (R)" [15] (pp.280-290). The event time (E) refers to the time when a described event occurs. The speech time (S) is the time of utterance. The reference time $(\mathrm{R})$ is the time for which, on some occasion, a claim is made. That is, $R$ is the time which can be identified by both the speaker and the hearer in an established scene/situation.

As in Fig. 2 and Fig. 3, the event of the resultative Expression involving BA is projected on the time scale of the past and the future, leading to the past perfect and the future perfect. Although Chinese does not have tense, a past reference and a future reference can be marked by temporal adjuncts such as zuotian ('yesterday') and mingtian ('tomorrow'). I firstly illustrate an instance of an Expression involving BA (6) which encodes a past event as in Fig. 2:

(6) Zuotian, wo BA ta tuo hui matou le. Yesterday 1 SG OBJ marker 3SG drag back to dock ASP

'I dragged him back to the dock yesterday.'

In the following Fig. 2, the representation of the perfective aspect of an Expression involving BA is the same with Figure 1 , but here the perfectivity is projected onto the time scale. Due to the existence of zuotian ('yesterday'), the event denoted by the sentence occurred in the past relative to the speech time (S). The event time (E) precedes both the speech time $(\mathrm{S})$ and the reference time $(\mathrm{R})$ in the temporal sequence. The event time (E) precedes the speech time (S) because the past event occurred obviously before the speaker uttered. The event time (E) also precedes the reference time (R) which is a past-time reference that can be identified by both the speaker and the hearer in the scenario. The duration of the event (intervening between the starting point and the finishing point) is highlighted in black shade. The result of the event is not seen until the finishing point (FP), and thus the end of the event time (E) coincides with the finishing point. In contrast, the starting point is not observable, as represented in broken square and projection line.

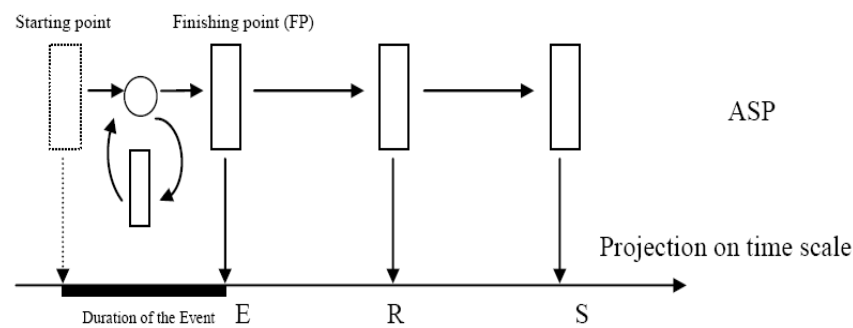

Fig. 2. Temporal reading of the past perfect of the resultative expressions involving BA.

The resultative Expression involving BA can also encode a future event by involving a temporal adjunct mingtian ('tomorrow'), as in (7):

(7) Mingtian, wo BA ta tuo hui matou. Tomorrow 1SG OBJ marker 3SG drag back to dock 'I will drag him back to the dock tomorrow.'

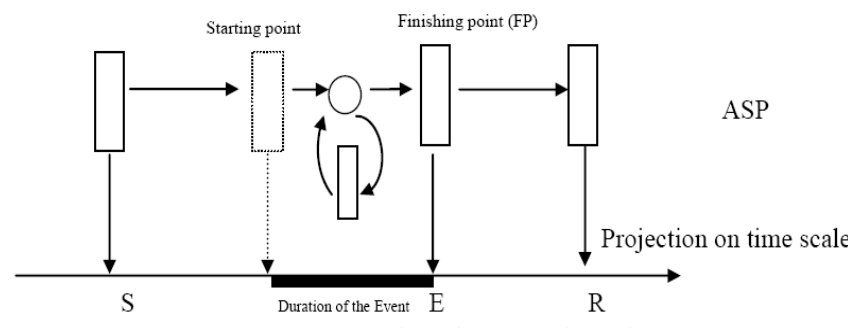

Fig. 3. Temporal reading of the future perfect of the Resultative Expressions involving BA.

I have discussed the perfective aspect of Expressions involving BA, as well as the representation of the past perfect and the future perfect.

\section{SEMANTICS OF THE BA EXPRESSIONS}

The last section discusses the semantics of the BA expression. Previous research has not offered a better account of describing the semantics of the BA expressions. For example, an Expression involving BA has been understood as a "disposal" pattern in literature: "The disposal form states how a person is handled, manipulated, or dealt with; how something is disposed of; or how an affair is conducted" [16]-[23]. Li and Thompson (1981) [24] (pp. 463-497)-[29] also claim that "disposal" refers to "what happens to the direct object". Here, "disposal" is not always true for the semantics of an Expression involving BA.

I am in favour of Li and Thompson (1981) holding that the resultative is in the heart of the semantics of Expressions 
involving $\mathrm{BA}$, considering the definition of the resultative: "The resultative expresses both a state and the preceding action it has resulted from" [30] (pp. 3-62)-[34]. An Expression involving BA features the action-result relation and thus satisfies the criterion of the resultative construction.

\section{CONCLUSION}

I have shown in this paper that an Expression involving BA is telic by using two criteria, i.e. "endpoint" and "non-homogeneity". The telicity is to a large extent contributed by the [+telic] feature of the resultative Expression involving BA per se, rather than (or, at least, not only due to) the aspect marker le, based on the contrast between the [+telic] Expression involving BA and the [-telic] transitive expression. An Expression involving BA depicts a telic event with an inherent entailment of completion: there is a culmination point at which the action designated by the main verb comes to an end and cannot continue further. Meanwhile, this paper finds that the resultative Expression involving BA is non-homogeneous.

While discussing the telicity in Expressions involving BA, it is necessary to consider the role of the resultative element as well. The study put forward the perfective aspectual model of the BA resultative and the aspectual analysis is further combined with a sequence of three distinct time points including Event Time (E), Speech Time (S), and Reference Time $(\mathrm{R})$ : the perfectivity is projected onto the time scale, including the past perfect and the future perfect. At last, I show that the semantic meaning of the BA expression is not disposal as stated in previous research, but resultative satisfying the criterion of action-result relation.

\section{REFERENCES}

[1] H. J. Verkuyl, On the Compositional Nature of the Aspects, Dordrecht: D. Reidel, 1972, pp. $42-49$.

[2] C. Smith, "A theory of aspectual choice," Language, vol. 59, pp. 479-501, Jan. 1983.

[3] C. Tenny, Aspectual Roles and the Syntax-Semantics Interface, Dordrecht: Kluwer Academic Publishers, 1994, pp. 150-180.

[4] M. Bennett and B. Partee, "Toward the logic of tense and aspect in English,” Indiana University Linguistics Club, 1972.

[5] B. Taylor, "Tense and continuity," Linguistics and Philosophy, vol. 1, no. 2, pp. 199-220, May 1977.

[6] D. Dowty, "The effect of aspectual classes on the temporal structure of discourse: Semantics or pragmatics," Linguistics \& Philosophy, vol. 9, pp. 37-61, April 1986.

[7] T. Reinhart, "States, events and reference time," MIT Lexicon Project, 1986.

[8] O. Borik, "Aspect and reference time," PhD Dissertation, University of Utrecht, Utrecht, 2002.

[9] R. Jackendoff, "The proper treatment of measuring out, telicity, and perhaps even quantification in English," Natural Language and Linguistic Theory, vol. 14, no. 2, pp, 305-354, 1996.

[10] A. van Hout, "Event semantics of verb frame alternations," $\mathrm{PhD}$ dissertation, Tilburg, 1996

[11] A. Hacohen, "The psychological reality of the telic/atelic distinction: Evidence from adult and child Hebrew," in Proc. the 21st Annual Meeting of the Israel Associations for Theoretical Linguistics, Israel, 2006, pp. 1-10.

[12] B. Comrie, Aspect: An Introduction to the Study of Verbal Aspect and Related Problems, Cambridge: Cambridge University Press, 1976, pp. 17-20.
[13] J. H.-Y. Tai, "Verbs and times in Chinese: Vendler's four categories," in Papers from the Parasession on Lexical Semantics, D. Testen, V. Mishra and J. Drogo, Eds. Chicago: Chicago University Press, 1984, pp. 287-296.

[14] C. S. Smith, The Parameter of Aspect, Dordrecht: Kluwer Academic Publishers, 1991, pp. 120-140.

[15] H. Reichenbach, Elements of Symbolic Logic, New York: The Macmillan Company, 1947, pp. 280-290.

[16] C. N. Li and S. A. Thompson, "Coverbs in Mandarin Chinese verbs or prepositions," Journal of Chinese Linguistics, vol. 2, no. 3, pp. 257-278, 1974.

[17] E. Hinrichs, "A compositional semantics for aktionsarten and NP reference," Ph.D. Dissertation, Ohio State University, Ohio, 1985.

[18] H. Filip, "Aspect, situation types and nominal reference," Ph.D Dissertation, University of California at Berkeley, Berkeley, 1993.

[19] H. Filip, Aspect, Situation Types and Noun Phrase Semantics, New York/London: Garland Publishing, 1999, pp. 60-90.

[20] H. Kamp and C. Rohrer, "Tense in text," in Meaning, Use and Interpretation in Language, R. Bauerle, C. Schwartze and A. von Stechow, Eds., Berlin: de Gryter Linguistik, 1983, pp. 45-52.

[21] H. Kamp and U. Reyle, From Discourse to Logic; Introduction of Model-Theoretic Semantics of Natural Language, Formal Logic and Discourse Representation Theory, Dordrecht, Boston and London: Kluwer Academic Publishers, 1993, pp. 121-130.

[22] M. Krifka, "The origins of telicity," in Events and Grammar, S. Rothstein, Ed. Dordrecht: Kluwer, 1998, pp. 197-235.

[23] B. Partee, "Nominal and temporal anaphora," Linguistics and Philosophy, vol. 7, pp. 243-286, 1984.

[24] C. N. Li and S. A. Thompson, The BA Construction, in Mandarin Chinese: A Functional Reference Grammar, Los Angeles: University of California Press, Los Angeles, 1981, pp, 463-491.

[25] O. Borik, Aspect and Reference Time, Oxford: Oxford University Press, 2006, pp. 12-130.

[26] C. C. Chu, "Some semantic aspects of action verbs," Lingua, vol. 40, pp. 43-54, July 1976.

[27] D. Bois and W. John, "Beyond definiteness: The trace of identity in discourse," in The Pear Stories: Cognitive, Cultural, and Linguistic Aspects of Narrative Production, W. Chafe, Ed. Norwood, NJ: Ablex, 1980, pp. 5-90.

[28] W. Klein, P. Li, and H. Henriette, "Aspect and assertion in Mandarin Chinese," Natural Language and Linguistic Theory, vol. 18, pp, 723-770, 2000.

[29] J. Maslov, "Resultative, perfect and aspect," in Typology of Resultative Constructions, V. Nedjalkov, Ed. Amsterdam: Benjamins, 1988, pp. 63-86.

[30] P. Nedjalkov and S. Jaxontov, "The typology of resultative construction," in Typology of Resultative Constructions, P. Nedjalkov, Ed. Amsterdam: John Benjamins, 1988, pp. 3-62.

[31] E. Sweetser, From Etymology to Pragmatics: Metaphorical and Cultural Aspects of Semantic Structure, Cambridge: Cambridge University Press, 1990, pp. 56-89.

[32] Y. Szeto, "A semantic description of the aspectual and temporal reference in Chinese," PhD Dissertation, University of Ottawa, Ottawa, 1988.

[33] G. Yang, "The semantic relation types of complex aspect and the directional requirements in generation," in Proc. the 5th Chinese Conference on Computational Linguistics, Beijing: Tsinghua University Press, pp. 21-26, 1999.

[34] Y. Yang and J. Kuo, "The Chinese temporal coverbs, postpositions, coverb-postposition pairs, and their temporal logic," Language, Information and Computation (PACLIC 12), pp. 18-20, Feb. 1998.

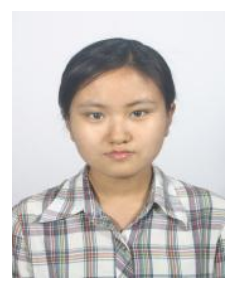

Jing Han was born in China, in February 1986. She received a $\mathrm{PhD}$ degree from University of Edinburgh, Edinburgh, UK, 2014.

She is working as a lecturer in Shanghai University, China with the current research interest of cognitive linguistics.

Dr. Han is a member of LAGB and IACL. 